\title{
Boosting of Markers of Fc $\gamma$ Receptor Function in Anti-HIV Antibodies During Structured Treatment Interruption
}

\author{
Hugh Billings, ${ }^{1}$ Bruce D. Wines, ${ }^{1-3}$ Wayne B. Dyer, ${ }^{4,5}$ Robert J. Center, ${ }^{6,7}$ \\ Halina M. Trist, ${ }^{1}$ Stephen J. Kent, ${ }^{7,8}$ and P. Mark Hogarth ${ }^{1-3}$
}

\begin{abstract}
Anti-HIV envelope (Env) antibodies elicit important Fc receptor functions, including Fc $\gamma$ RIIIa-mediated natural killer cell killing of opsonized infected targets. How these antibodies evolve during HIV infection and treatment remains poorly understood. We describe changes in anti-HIV Env IgG using longitudinal samples from seroconverter subjects treated soon after infection and later during periods of structured treatment interruption (STI). Our well-validated dimeric $\mathrm{rsF} \gamma \gamma \mathrm{R}$ binding assays combine effects of opsonizing antibody subclasses, epitopes, and geometries to provide a measure of $\mathrm{Fc} \gamma \mathrm{R}$ ( $\mathrm{Fc} \gamma$ receptor)-mediated functionality. IgG1 anti-Env titers diminished rapidly during antiretroviral therapy (ART; $\mathrm{t}_{1 / 2} 3.0 \pm 0.8$ months), while the dimeric rsFc $\gamma \mathrm{RIII}$ activity persisted longer ( $\mathrm{t}_{1 / 2} 33 \pm 11$ months), suggesting that there is maintenance of functional antibody specificities within the diminished pool of anti-HIV Env Abs. The initial antibody response to infection in two subjects was characterized by approximately fivefold higher Fc $\gamma$ RIIIa compared with Fc $\gamma$ RIIa binding activity. Uncoupling of Fc $\gamma$ RIIa and Fc $\gamma$ RIIIa activities may be a distinct feature of the early antibody response that preferentially engages Fc $\gamma$ RIIIa-mediated effector functions. Two to three STI cycles, even with low viremia, were sufficient to boost dimeric Fc $\gamma \mathrm{R}$ activity in these seroconverter subjects. We hypothesize that increased humoral immunity induced by STI is a desirable functional outcome potentially achievable by therapeutic immunization during ART. We conclude that controlled viral antigen exposure under the protection of suppressive ART may be effective in eliciting Fc $\gamma$ R-dependent function in support of viral reactivation and kill strategies.
\end{abstract}

Keywords: Fc receptor, anti-envelope antibody, ART

\section{Introduction}

$\mathbf{L}$ EUKOCYTE ACTIVATION THROUGH IgG binding to Fc $\gamma$ receptors ( $\mathrm{Fc} \gamma \mathrm{Rs})$ is key to IgG-induced protective inflammatory responses, antibody-dependent cellular cytotoxicity (ADCC), antibody-dependent cellular phagocytosis (ADCP), antibody-dependent cellular viral inhibition, and antigen presentation. ${ }^{1-4} \mathrm{Fc} \gamma \mathrm{R}$-mediated functions augment protective antibody responses to HIV infection in macaques, mice, and humans. ${ }^{5,6} \mathrm{~A}$ component of protection and viremic control in macaque vaccination and challenge studies is contributed by Fc-dependent functions, such as ADCC and ADCP. ${ }^{7-11}$ In addition to neutralizing activity, BnAbs clear infected cells mediated through Fc $\gamma \mathrm{R}$ binding ${ }^{12}$ and stimulation of the endogenous antibody response. ${ }^{13,14}$ However, highly protective $\mathrm{BnAbs}$ are rarely found in long-term

\footnotetext{
${ }^{1}$ Immune Therapies Group, Life Sciences, Burnet Institute, Melbourne, Australia.

${ }^{2}$ Department of Immunology, Monash University Central Clinical School, Melbourne, Australia.

${ }^{3}$ Department of Pathology, The University of Melbourne, Melbourne, Australia.

${ }^{4}$ Australian Red Cross Blood Service, Alexandria, Australia.

${ }^{5}$ School of Medical Science, Faculty of Medicine and Health, University of Sydney, Sydney, Australia.

${ }^{6}$ Department of Microbiology and Immunology, Peter Doherty Institute for Infection and Immunity, University of Melbourne, Melbourne, Australia.

${ }^{7}$ Disease Elimination, Life Sciences, Burnet Institute, Melbourne, Australia.

${ }^{8}$ Department of Infectious Diseases, Melbourne Sexual Health Centre, Alfred Health, Central Clinical School, Monash University, Melbourne, Australia.
}

(C) Hugh Billings et al. 2019; Published by Mary Ann Liebert, Inc. This Open Access article is distributed under the terms of the Creative Commons License (http://creativecommons.org/licenses/by/4.0), which permits unrestricted use, distribution, and reproduction in any medium, provided the original work is properly cited. 
infected individuals and are not induced by current immunization strategies. Hence, $\mathrm{Fc} \gamma \mathrm{R}$-mediated functions may be of particular importance early in infections.

Only one human vaccine trial (RV144) demonstrated efficacy against HIV-1 infection and this was mediated by antibody Fc $\gamma$ R binding. Protective efficacy was a low $31.2 \%$ and short-lived, ${ }^{15}$ and $\mathrm{ADCC} / \mathrm{Fc}$ effector functional antibodies in the absence of an IgA response correlated with protection, ${ }^{15-17}$ whereas neutralizing antibody and cytotoxic $\mathrm{T}$ lymphocyte (CTL) responses were comparatively weak. ${ }^{18}$ In contrast to the unsuccessful VAX003 trial, the RV144 vaccine generated non-neutralizing Abs with multiple Fc $\gamma \mathrm{R}$ functions, with higher IgG1 and IgG3 levels. ${ }^{19}$ These studies support a critical role for $\mathrm{IgG} \mathrm{Fc} \gamma \mathrm{R}$ binding activity in protection from HIV infection.

Combination antiretroviral therapy (ART) has effectively controlled HIV replication and limited transmission for over two decades, ${ }^{20}$ but a cure remains elusive. Potential cure strategies based on shock and kill approaches are in early stages of investigation. ${ }^{21}$ Complete clearance of the viral reservoir may depend on an immune component ${ }^{22,23}$ and is likely to require $\mathrm{Fc}$-mediated effector functions for optimal efficacy. ${ }^{24,25}$

ART commenced early in HIV-1 infection reduces antiHIV IgG antibody-secreting cells ${ }^{26}$ and serum antibodies, ${ }^{27,28}$ which is opposite to what may be required for virus reactivation and cure strategies. Moreover, the impact of ART on the half-life of anti-Env Ab titers and ADCC functional antibodies is poorly defined. ${ }^{29,30}$ Since $\mathrm{Ab}$ titers rebound more rapidly during ART interruption compared with initial infection, ${ }^{28}$ and HIV+ individuals on ART respond well to influenza A vaccination, ${ }^{31}$ vaccination to boost antibodies mediating ADCC could form part of an eradication strategy in patients on suppressive ART.

We investigated engineered dimeric ectodomains of $\mathrm{Fc} \gamma \mathrm{Rs}$ as functional markers of the humoral response to HIV. These bind closely spaced $\mathrm{IgG} \mathrm{Fc}$ pairs to mimic the engagement and cross-linking of $\mathrm{Fc} \gamma \mathrm{R}$ pairs by IgG-opsonized virus or infected cells. ${ }^{32-36}$ Binding is further influenced by the $\operatorname{IgG}$ subclass and, in the case of Fc $\gamma$ RIIIa, glycosylation of the Fc domain. ${ }^{37}$ We examined longitudinal serum samples from HIV-infected subjects, who commenced ART close to the time of seroconversion, to address the Fc receptor-mediated functionality of anti-HIV Ab responses early in infection, their decline during ART, and boosting during structured treatment interruption (STI). The combined effects of host immune responses on viral containment are discussed in the context of viral eradication strategies.

\section{Materials and Methods}

\section{Study participants}

We recruited newly infected individuals to a study of antiviral immunity during ART. Baseline specimens were obtained before or shortly after commencing ART. Serum and plasma specimens were provided by the Immunovirology Research Network of the Australian Centre for HIV and Hepatitis Virology Research and the Victorian HIV Blood and Tissue Storage Bank, Alfred Hospital. The respective human research ethics committees approved the study. Three patients subsequently participated in a pilot assessment of STI aimed at boosting antiviral immunity, after at least
6 months of undetectable viremia on ART. The number of patients given STI was small because we discontinued recruitment for this pilot after reports that time-based STI could result in viral reservoir reseeding and induce viral resistance. ${ }^{38}$ Patients on continuous ART and patients with poor treatment adherence (e.g., SC49) acted as comparators for STI participants. Blood specimens were taken on monthly visits or weekly during the STI phase.

\section{Reagents, Abs, and HIV-1 antigens}

Albumin, bovine fraction V (BSA), and casein sodium salt were from Sigma-Aldrich. A chimeric IgG1 comprising a mouse leader and VH sequence (from TIB142 antitrinitrophenyl [TNP]; American Type Culture Collection) joined to a human IgG1 C region sequence (IgG1 anti-TNP) was previously described. ${ }^{39}$ Biotin mouse anti-huIgG1 (A10650, clone HP6069), biotin mouse anti-huIgG3 (053640, clone HP6047), and 3,3',5,5'-tetramethylbenzidine (TMB) enzyme-linked immunosorbent assay (ELISA) substrate and the high-sensitivity streptavidin-horseradish peroxidase (HRP) conjugate were from Thermo Fisher (Melbourne, Australia). HIV-1 gp140 AD8 was as previously described. ${ }^{40,41}$

\section{Determination of rsFcy $R$ binding by Ab-opsonized gp140 in the ELISA}

ELISA plates (MaxiSorp; Nunc) were coated with HIV-1 Env antigen gp140-AD8 Env or gp120 $0^{40,41}$ in phosphatebuffered saline (PBS) $/ 1 \mathrm{mM}$ EDTA (PBSE) at $50 \mathrm{ng} / 50 \mu \mathrm{L}$ per well and blocked with PBSE/5\% casein sodium salt (SigmaAldrich). Patient samples were incubated with $1 \%$ NP40 at $42^{\circ} \mathrm{C}$ for $30 \mathrm{~min}$, appropriately diluted in PBSE $/ 1 \% \mathrm{BSA}$, and incubated in wells for $2 \mathrm{~h}$ at $37^{\circ} \mathrm{C}$. MAbs b12, PGT121, and 2G12 were kindly provided by Dennis Burton, The Scripps. Plates were then incubated with biotinylated rsFc $\gamma$ RIIa (H131 allele at $0.2 \mu \mathrm{g} / \mathrm{mL}$ ) or $\mathrm{rsFc} \gamma \mathrm{RIIIa}$ (V158 allele at $0.1 \mu \mathrm{g} / \mathrm{mL}$ ) and detected with TMB, as described previously. ${ }^{37}$

\section{Determination of IgG subclass levels among Ab-opsonized gp140 titers}

Anti-gp140-AD8 titers were measured in NP40-treated serum/plasma, diluted 1:20 to 1:6,400 for IgG1. IgG3 was not detected at high dilution as was IgG1, and IgG3 levels are reported as absorbance units (AU) at 1:5 dilution. Detection was performed with biotinylated mouse anti-huIgG1 (A10650, clone HP6069; Thermo Fisher) or mouse anti-IgG3 (05-3640, clone HP6047; Thermo Fisher) at $1 \mu \mathrm{g} / \mathrm{mL}$ in $\mathrm{PBS} / 1 \% \mathrm{BSA}$ for $1 \mathrm{~h}$ at $37^{\circ} \mathrm{C}$, followed by $1: 10,000$ highsensitivity streptavidin-HRP conjugate (Pierce, Thermo Fisher) in PBS/1\% BSA for $1 \mathrm{~h}$, then developed with TMB.

\section{Antiviral $T$ cell responses}

Assays for CD4 $\mathrm{T}$ cell proliferative responses to HIV-1 p24 antigen and CD8 responses determined by IFN- $\gamma$ ELISPOT are described elsewhere. ${ }^{42,43}$

\section{Data and statistical analysis}

Statistical analysis and curve fitting (Table 1) were performed with GraphPad Prism, version 7 (GraphPad, San 
Table 1. Baseline Characteristics and Decline in Serological Parameters During Antiretroviral Therapy

\begin{tabular}{|c|c|c|c|c|c|c|c|c|}
\hline \multirow[b]{3}{*}{ Subject } & \multirow{3}{*}{$\begin{array}{c}\text { CD4 } \\
\text { baseline }^{\mathrm{a}}\end{array}$} & \multirow{3}{*}{$\begin{array}{c}C D 4, \\
\text { average } \pm S D\end{array}$} & \multirow[b]{3}{*}{ Initial $V L^{\mathrm{b}}$} & \multirow{3}{*}{$\begin{array}{l}\text { Initial IgG1 } \\
\text { titer DF50 }\end{array}$} & \multicolumn{4}{|c|}{$\begin{array}{l}\text { Half-life of serological parameters, } \\
t_{1 / 2} \text { (months) }\end{array}$} \\
\hline & & & & & \multirow[b]{2}{*}{ IgG1 titer ${ }^{\mathrm{d}}$} & \multicolumn{3}{|c|}{ Dimeric $r s F c \gamma R$ binding $^{\mathrm{e}}$} \\
\hline & & & & & & $F c \gamma R I I a$ & $F_{c} \gamma R I I b$ & Fc $\gamma R I I I a$ \\
\hline SC22 & 800 & $903 \pm 193$ & 3,800 & 6,400 & $3.9(0.7)^{\mathrm{f}}$ & $8.1(0.6)$ & $9.4(0.9)$ & $54(0.5)$ \\
\hline SC61 & 510 & $704 \pm 152$ & 6,200 & 6,000 & $3.8(0.7)$ & $13.3(0.5)$ & $22.1(0.9)$ & $70(0.6)$ \\
\hline SC68 & 800 & $799 \pm 222$ & 460,000 & 3,200 & $0.5(0.6)$ & $3.4(0.8)$ & $3.2(0.9)$ & $4.5(0.9)$ \\
\hline SC15 & 610 & $935 \pm 189$ & 190,000 & 2,200 & $3.3(0.9)$ & $12.5(0.6)$ & $4.2(0.9)$ & $15.5(0.8)$ \\
\hline $\mathrm{SC} 24$ & 471 & $582 \pm 126$ & UD & 1,200 & $0.7(0.9)$ & $42.6(0.7)$ & ND & $85.7(0.7)$ \\
\hline SC74 & 670 & $831 \pm 201$ & UD & 820 & $1.7(0.6)$ & $6.6(0.9)^{f}$ & $1.5(0.9)$ & $16(0.8)$ \\
\hline SC21 & 736 & $928 \pm 229$ & UD & 473 & $7.7(0.9)$ & $4.2(0.8)$ & ND & $12.4(0.8)$ \\
\hline SC84 & 722 & $860 \pm 150$ & UD & 188 & ND & ND & ND & ND \\
\hline SC49 & 430 & $764 \pm 178$ & 3,840 & 97 & $2.6(0.9)^{\mathrm{f}}$ & ND & ND & $1.7(0.9)^{f}$ \\
\hline Mean \pm SEM & $639 \pm 47$ & $812 \pm 39$ & & $2,290 \pm 811$ & $3.0 \pm 0.80$ & $13.0 \pm 5.0$ & $8.1 \pm 3.7$ & $33 \pm 11$ \\
\hline
\end{tabular}

Values in brackets are $r^{2}$ correlation coefficients for curve fitting.

${ }^{a}$ CD4 counts for SC24 and SC21 were determined 5 and 0.4 months after study commencement, averaged counts are across the whole study period.

${ }^{\mathrm{b}} \mathrm{VL}$, viral load at the start of the study. Viremia was UD in four subjects who commenced ART before baseline assessment.

${ }^{\mathrm{c}} \mathrm{IgG} 1$ titer is defined as the dilution factor giving 50\% of maximal signal; half-lives of serological parameters during ART were determined by curve fitting.

${ }^{\mathrm{d}}$ To agonist versus response curve (variable slope).

${ }^{\mathrm{e}}$ To inhibitor versus response curves (also Figs. 1 and 2).

${ }^{\mathrm{f}}$ Determined by linear fit.

ART, antiretroviral therapy; ND, not determined; SD, standard deviation; SEM, standard error of the mean; UD, undetectable.

Diego, CA). Dimeric $\mathrm{rsFc}_{\gamma} \mathrm{R}$ binding activities are reported as AU background (Figs. 1 and 4-Fc $\gamma$ RIIa only) or as AU normalized to $\mathrm{rsFc} \gamma \mathrm{R}$ binding to $\operatorname{IgG1}$ anti-TNP ${ }^{37}$ at $0.5 \mu \mathrm{g} / \mathrm{mL}$. Differences in binding activity were determined by Mann-Whitney $t$-tests (Fig. 3) or ANOVA.

\section{Results}

The dimeric rsFcy $R$ assay and anti-lgG are different measures of gp140 opsonization

Saturating levels of monoclonal $(20 \mu \mathrm{g} / \mathrm{mL})$ or polyclonal antibodies (pAbs) were used to opsonize AD8 gp140. Binding of the IgG1 mAbs and pAbs to gp140 was detected with anti-IgG (Fig. 1A), and the capacity of this opsonized gp140 to bind dimeric rsFc $\gamma$ RIIa was also determined (Fig. 1B). While the level of bound IgG was lower for mAbs than pAbs, only the pAb-opsonized gp140 bound dimeric $\mathrm{rsFc} \gamma \mathrm{R}$. In contrast, the bound mAbs, separately or in combination, were undetected by the dimeric $\mathrm{rsF} \gamma \gamma \mathrm{R}$ reagent. Thus, in subsequent dimeric $\mathrm{rsF} \gamma \gamma \mathrm{R}$ assays, low dilution of samples was used to allow high occupancy of gp140 and so favor formation of pairs of opsonizing IgG antibodies that support dimeric receptor binding.

\section{Decline in humoral responses in seroconverters on ART}

IgG1 is the predominate antibody binding $\mathrm{Fc} \gamma \mathrm{Rs}$ and so the effect of early ART on anti-HIV Env IgG1 titers and dimeric $\mathrm{rsFc} \gamma \mathrm{R}$ binding activity was determined (Table 1). The initial IgG1 anti-Env titers were very low in subjects who were either treated very early (e.g., SC49) or treated before the baseline sample was taken (e.g., SC74). Uninterrupted ART controlled the viral load (VL) to undetectable levels in the majority of subjects as expected, and uninterrupted ART was associated with a decline of the IgG1 anti-Env titer $\left(\mathrm{DF}_{50}\right.$ of $2,550 \pm 870)$ with a short half-life $\left(\mathrm{t}_{1 / 2}\right)$ of $3.0 \pm 0.8$ months (Table 1). At low dilution, the loss of Env-specific pAb IgG capable of Fc $\gamma$ RIIIIa dimer binding was slower $(p=.023)$ with a $t_{1 / 2}$ of $33 \pm 11.0$ months. This indicated that the diversity of $\mathrm{IgG}$ antibody specificities comprising the pAb response, necessary for dimeric $\mathrm{rsF} \gamma \mathrm{R}$ binding, was relatively retained during the decline of antibody titer (Table 1and Fig. 2). The loss of dimeric Fc $\gamma$ RIIa binding activity also trended toward a slower decline with $t_{1 / 2}$ of $13.0 \pm 5.0$ and $8.1 \pm 3.7$ months for dimeric $\mathrm{rsF} \gamma \gamma$ RIIa and dimeric $\mathrm{rsFc} \gamma \mathrm{RIIb}$, respectively.

Features of the humoral response were contrasted for two subjects, SC15 and SC61, with stronger initial anti-Env IgG1 titers (DF50 2,200 and 6,000, respectively) and two subjects, SC49 and SC74, with undetectable VL at baseline and low initial IgG1 responses (DF50 97 and 820, respectively). In SC49 and SC74, the early Fc $\gamma$ RIIIa activity was dominant (Fig. 3O, P) and Fc $\gamma$ RIIa activity (Fig. 3K, L) was low, with a ratio of Fc $\gamma$ RIIIa/Fc $\gamma$ RIIa binding of $\sim 6$ for SC49 and SC74 (Fig. 3W, $\mathrm{X})$. Furthermore, although $\mathrm{IgG} 3$ levels were low, the ratio of IgG3/IgG1 (AU/titer) was up to 10-fold higher in SC49 and SC74 (Fig. 3S, T) compared with SC15 and SC61 (Fig. 3Q, R).

\section{Humoral response in a subject with viral rebound during poor ART compliance}

Suppressive ART very early after infection in SC49 controlled a brief viremia, with low anti-Env IgG1 titer and IgG3 levels peaking around 2-3 months (Fig. 4A, B). These humoral responses declined during ART, but were boosted upon viremia during a period of poor ART compliance ( $>9$ months). Dimeric rsFc $\gamma$ RIIa-H131 binding activity was initially low (Figs. 3K and 4B), but increased 20-fold $(p<.05)$ 

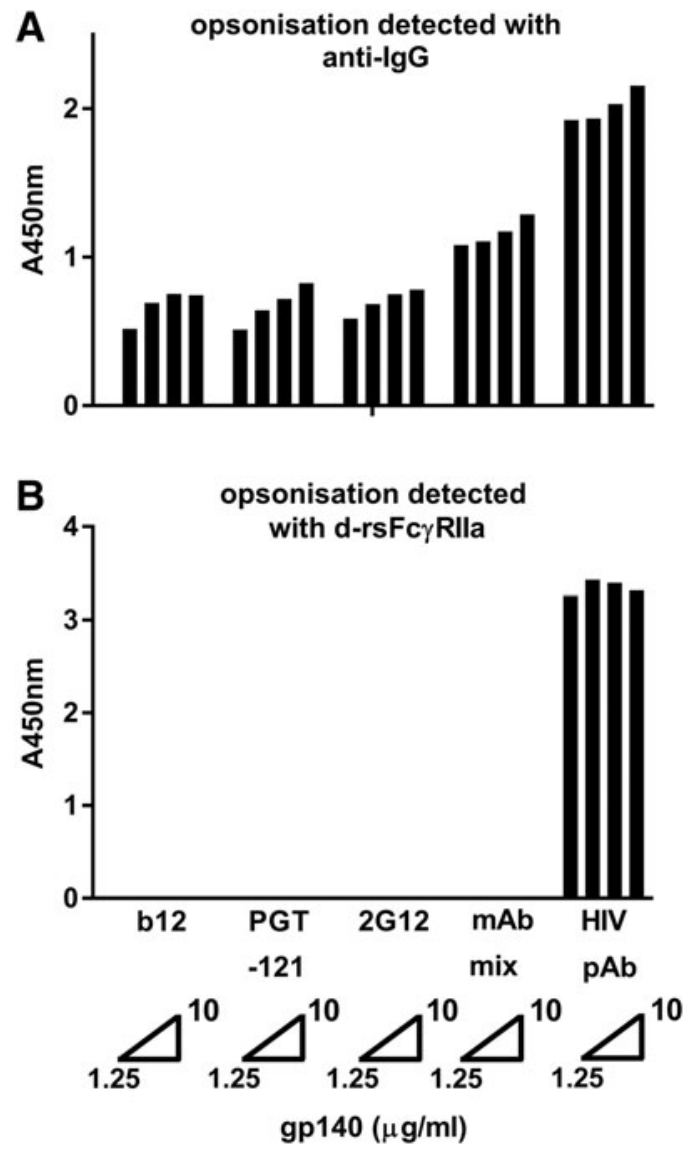

FIG. 1. rsFc $\gamma$ RIIa dimer binding to IgG-opsonized envelope is dependent on the clonal diversity (polyclonality) of opsonizing Abs. HIV Env gp140-AD8 was coated at concentrations of $1.25,2.5,5$, or $10 \mu \mathrm{g} / \mathrm{mL}$ and opsonized with $\mathrm{HIV}+$ patient serum at $1 / 2,000$ dilution $(\sim 5-10 \mu \mathrm{g} / \mathrm{mL}$ total Abs) or three mAb IgG antibodies, separately (at $20 \mu \mathrm{g} / \mathrm{mL}$ ) and in combination (mAb mix, $60 \mu \mathrm{g} / \mathrm{mL}$ total), (A) antiIgG binding and (B) dimeric rsFc $\gamma$ RIIa-H131 binding.

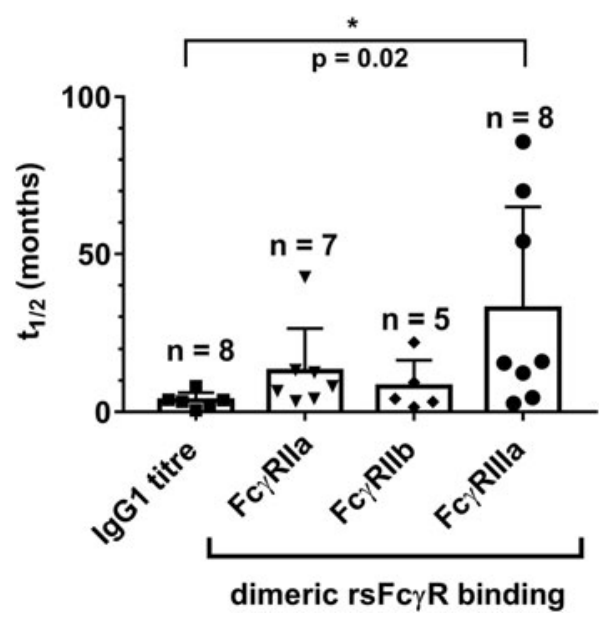

FIG. 2. Anti-Env IgG1 titer and dimeric $r s F c \gamma R$ binding activity decline during ART. Mean half-lives $\left(\mathrm{t}_{1 / 2}\right) \pm \mathrm{SEM}$ ( $n=5-8$ as indicated), one-way ANOVA, Tukey's multiple comparison test, $* p<.05$. ART, antiretroviral therapy; SEM, standard error of the mean. during poor ART compliance, while the IgG1 titer only increased twofold (Fig. 4A, B). Likewise, dimeric $\mathrm{rsFc}_{\gamma} \mathrm{RIIb}$ activity was also weak during the initial phase (Fig. 4C), but increased fourfold during poor ART compliance $(p<.01)$.

Unlike dimeric rsFc $\gamma$ RII activity, dimeric rsFc $\gamma$ RIIIa binding activity was robust in the early humoral response to infection (Figs. $3 \mathrm{O}$ and 4C), peaking around 1 month postinfection. During poor ART compliance, dimeric rsFc $\gamma$ RIIIa binding activity increased to only 1.3 -fold higher than the initial peak activity (Fig. 4C). Thus, in the initial response to infection, dimeric rsFc $\gamma$ RIIIa activity was greater than that of dimeric $\mathrm{rsFc} \gamma \mathrm{RII}$.

\section{Boosted humoral response in a subject that failed to control viremia during STI}

Subject SC21 commenced ART 1 month before the study and had undetectable baseline VL. Viral rebound occurred during each STI, and extremely high viral rebound occurred during the final interruption cycle, prompting permanent resumption of ART (Fig. 5). Increased IgG1 levels and dimeric rsFc $\gamma$ RIIa and dimeric rsFc $\gamma$ RIIIa binding activities occurred within weeks of low viral recrudescence during the first ART interruption (VL $=460$ copies $/ \mathrm{mL}$ ) and second ART interruption cycles (Fig. 5A, B).

The kinetics of HIV-specific $\mathrm{T}$ cell responses relative to $\mathrm{Fc} \gamma \mathrm{R}$-mediated Ab function during early treatment and ART interruption is not known. The p24 proliferative response (a marker of HIV-specific CD4 T cell responses) was sensitive to viral replication and declined after increased viremia (Fig. 5B), while the IFN $\gamma$ ELISPOT response (generally a marker of CD8 $\mathrm{T}$ cell responses), particularly to Pol peptides, remained relatively robust (Fig. 5C). Thus, while a small number of STIs boosted the dimeric $\mathrm{rsFc} \gamma \mathrm{R}$ binding activity and increased $\mathrm{T}$ cell responses, these did not prevent the high viral rebound, which was only controlled by resumption of ART.

\section{Boosted immune responses in subjects with viral control}

Subjects SC24 and SC84 had undetectable VL on ART at recruitment before several short periods of STIs and a final STI of about 10 months. SC24 had two short STIs, and during the final extended STI, a spike in viremia $(20,000$ viral copies/mL at 46 months) was followed by a rapid increase in anti-Env IgG1 levels, dimeric rsFc $\gamma$ RIIa binding activity, and virological control. Virological control was not sustained, with VL fluctuating between 140 and 3,600 copies/mL in the following 9 months (Fig. 6A, B). The first STI for SC24 (42 months) had no detectable viral replication ( $<50$ copies $/ \mathrm{mL}$ ) and low levels of both $\mathrm{IgG}$ and dimeric rsFc $\gamma$ RIIa binding activity (Fig. 6A). When assayed at low dilution, the initial STI trended toward an increase in both dimeric rsFc $\gamma$ RIIa and dimeric rsFc $\gamma$ RIIIa binding activities (Fig. 6B, C).

$\mathrm{T}$ cell response to changes in ART and viral replication in SC24 were also associated with possible long-term control of viremia after ceasing ART. The p24 proliferative response fluctuated during STIs and remained elevated immediately after the initial peak viral rebound during ART cessation (Fig. 6C). During the extended STI, the CD8 T cell response to env antigens increased $\sim 10$-fold and remained elevated (Fig. 6D). 

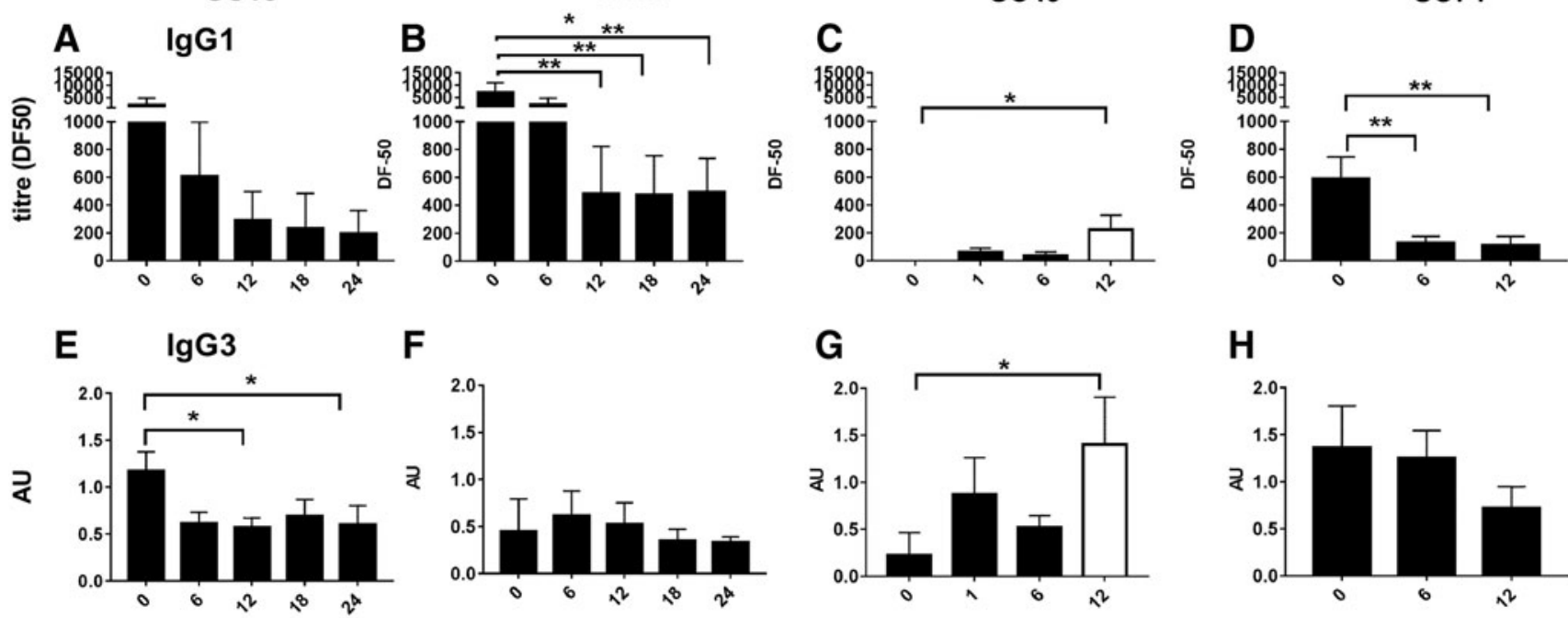

H
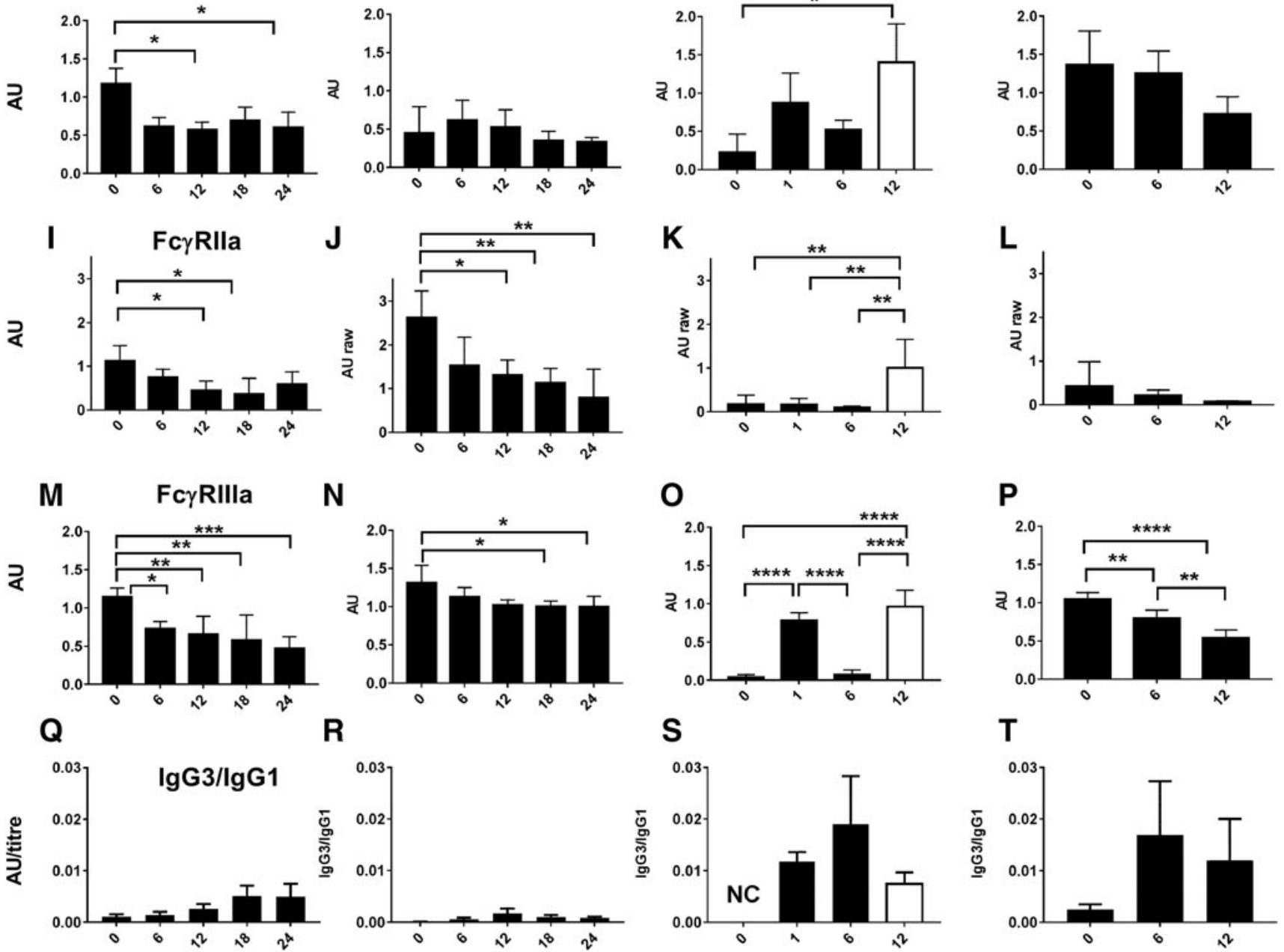

\section{U}

V
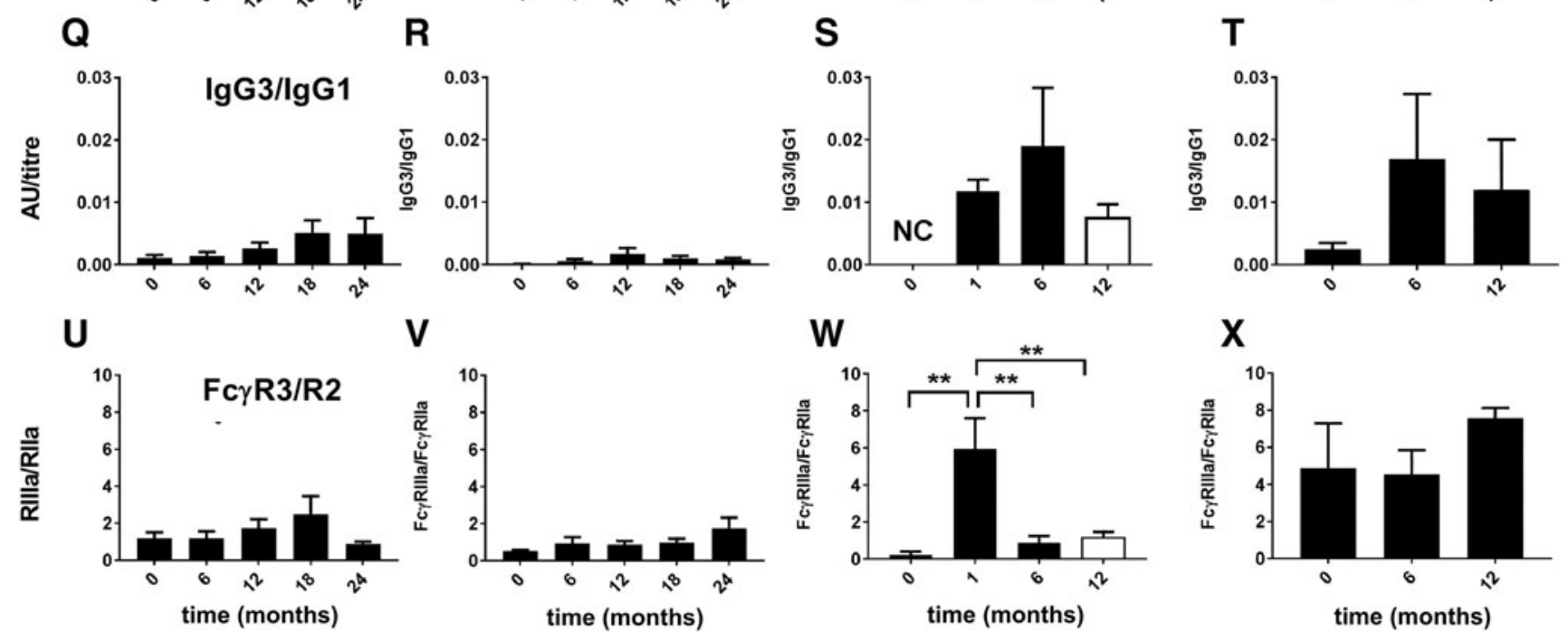

$\mathbf{X}$

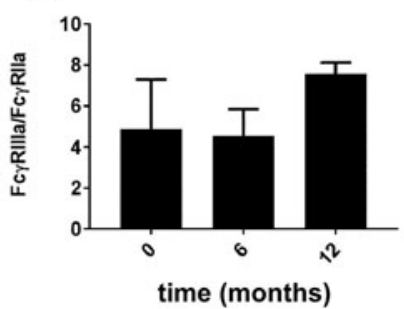

FIG. 3. The anti-HIV IgG response and Fc $\gamma \mathrm{R}$ activities were detected in SC samples by ELISA using immobilized AD8gp140; (A-D) opsonizing IgG1 titer, mean DF50 \pm range ( $n=3$ ); (E-H) opsonizing IgG3, AU \pm range (at 1/5 dilution, $n=3$ ); (I-P) dimeric rsFc $\gamma \mathrm{R}$ binding to Env opsonized with serum samples or plasma at 1/50 dilution was measured and (I-L) dimeric $\mathrm{rsFc} \gamma \mathrm{RIIa}$ activity presented as mean $\mathrm{AU} \pm \mathrm{SEM}, n=4$; (M-P) dimeric rsFc $\gamma \mathrm{RIIIa}$ activity (mean normalized $\mathrm{AU} \pm \mathrm{SEM}, n=4)$; $(\mathbf{Q}-\mathbf{T})$ the ratio of $\mathrm{IgG} 3, \mathrm{AU} / \mathrm{IgG} 1$ titer, mean DF50; and $(\mathbf{U}-\mathbf{X})$ the ratio of dimeric $\mathrm{rsFc} \gamma \mathrm{RIIIa}$ activity/dimeric rsFc $\gamma$ RIIa activity. The open bars indicate an off-ART sample for SC49. Change from baseline was assessed by one-way ANOVA, Tukey's multiple comparison test, ${ }^{*} p<.05, * * p<.01, * * * p<.001$, and $* * * * p<.0001$. $\mathrm{AU}$, absorbance units; ELISA, enzyme-linked immunosorbent assay; Fc $\gamma \mathrm{R}, \mathrm{Fc} \gamma$ receptor; SC, seroconverter. 

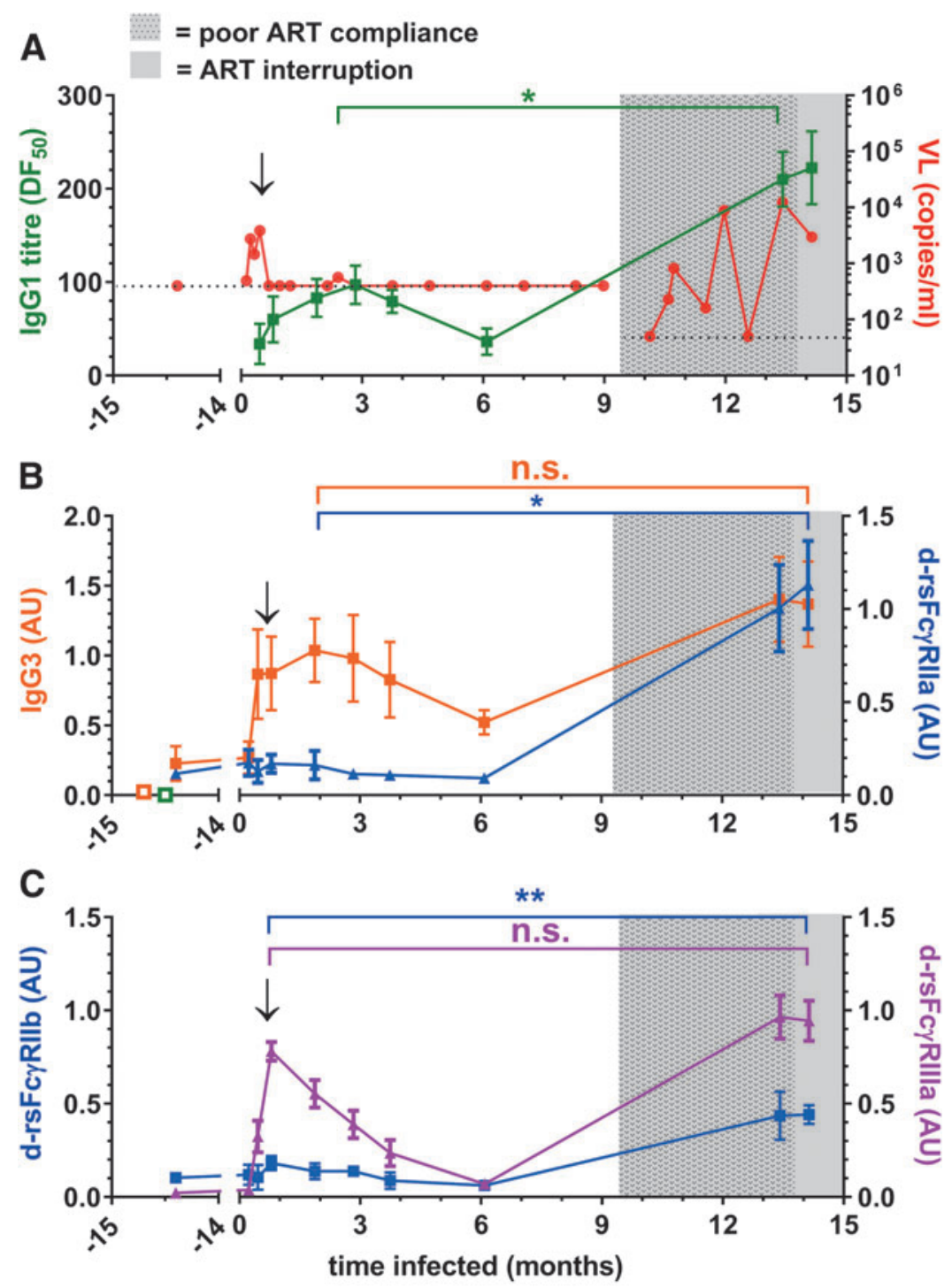

FIG. 4. The initial anti-HIV IgG response of patient SC49 had high dimeric rsFc $\gamma$ RIIIa activity and low Fc $\gamma$ RII binding activity. (A) Left axis (green symbols) AD8-gp140 opsonizing IgG1 titer, mean DF50 \pm range ( $n=3$ ); right axis (red symbols) viral load (Roche) is shown with dotted lines for the assay detection limits at 400 and subsequently 50 viral copies per milliliter. (B) Left axis (orange closed symbols), opsonizing IgG3 levels at 1/5 dilution, mean AU \pm range, $n=3$, open symbols show HIV-human serum samples $(n=3$ ), background anti-IgG1 (green), and anti-IgG3 (orange) binding to gp140; right axis, dimeric rsFc $\gamma$ RIIa-H131, AU binding to AD8-gp140 opsonized at 1/50 sample dilution, mean \pm SEM, $n=4$. (C) Left axis, dimeric rsFc $\gamma \mathrm{RIIb}$ binding (blue symbols), normalized AU, and right axis filled triangle (magenta) dimeric rsFc $\gamma \mathrm{RIII}-\mathrm{V} 158$ binding, normalized AU. The arrow marks the time of ART initiation, and the period of poor ART compliance is shown by a hatched gray background pattern and complete ART removal is indicated by the plain gray background. Means for the early and late peak activities were compared using an unpaired Mann-Whitney $t$-test, ${ }^{*} p<.05$ and $* * p \leq .01$.

In contrast to SC24, the first STI for subject SC84 was longer and resulted in high viremia ( $>750,000$ copies $/ \mathrm{mL})$ that was rapidly controlled by resumption of ART (Fig. 7A). This viremia stimulated marked increases in $\mathrm{Ab}$ levels and dimeric $\mathrm{rsF} \gamma \mathrm{RIIa}$ and dimeric $\mathrm{rsFc} \gamma \mathrm{RIII}$ a binding activities (Fig. 7A, B). During two short subsequent STI cycles, viral rebounds were greatly reduced $(<750$ copies $/ \mathrm{mL})$. After ceasing ART, further enhanced dimeric $\mathrm{rsFc} \gamma \mathrm{R}$ activities were contemporaneous with cyclic fluctuations in viremia with periodic control to $<1,000$ copies $/ \mathrm{mL}$.

The $\mathrm{T}$ cell proliferative response to $\mathrm{p} 24$ was sensitive to viral rebound, declining during peak viremia and then increasing during subsequent control when ART recommenced
(Fig. 7B). This helper $\mathrm{T}$ cell response was boosted after ceasing ART with an inverse association with viremia during cyclic control in the absence of ART. The CD8 T cell responses increased proportionally with viral rebound during ART interruption and after ceasing ART (Fig. 7C). The p24 proliferative response eventually declined, whereas humoral responses were maintained upon 12-month follow-up.

\section{Discussion}

This study of subjects treated with ART early after infection was designed to determine if short periods of viral antigen exposure experienced during STI could boost functional 


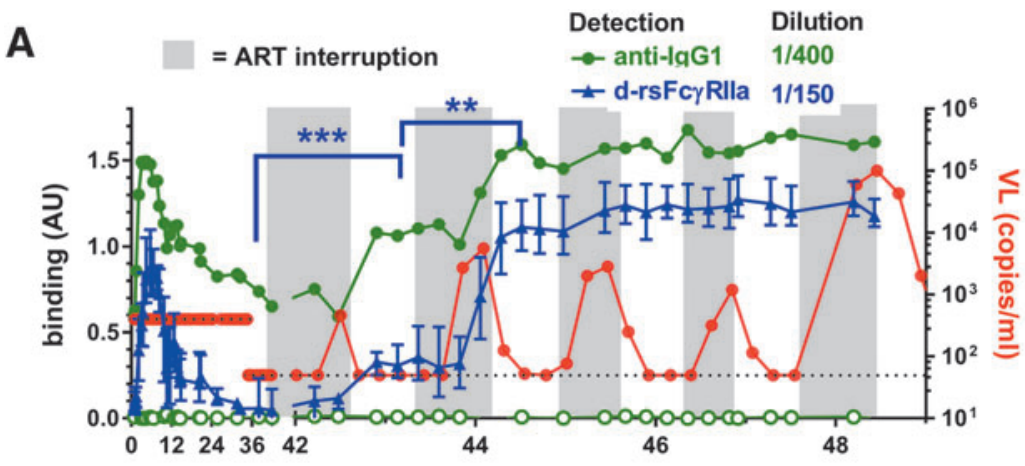

B
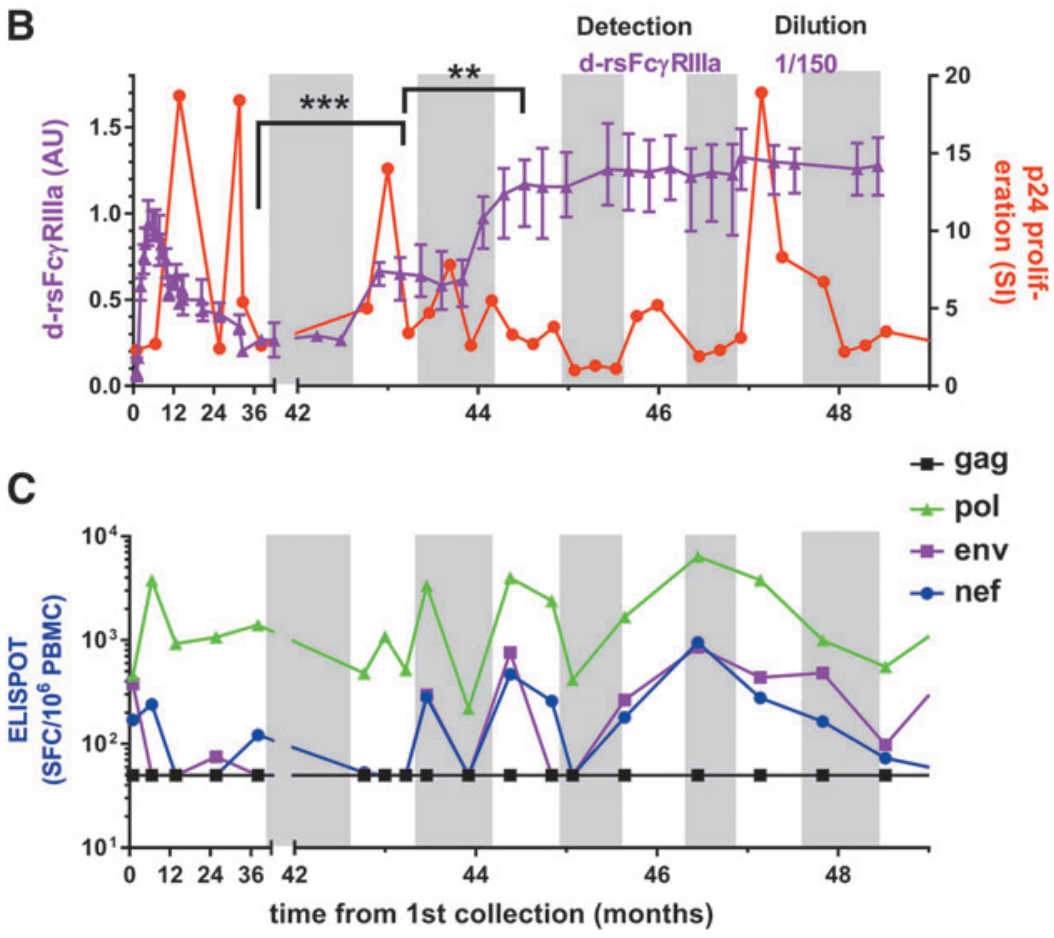

FIG. 5. STI in subject SC21 allowed viral rebound and stimulated stepwise boosting of anti-Env IgG1 and dimeric $\mathrm{rsF} \gamma \gamma \mathrm{R}$ activity. (A) Left axis, dimeric rsFc $\gamma$ RIIa-H131 binding to Env opsonized with a 1/150 dilution of samples (normalized $\mathrm{AU}$, mean \pm range, $n=3$, blue symbols) and anti-IgG1 binding to a $1 / 400$ dilution of samples with and without gp140 (green closed and open symbols, respectively). Right axis, viral load (red symbols) is shown with dotted lines indicating the assay detection limits at 400 and subsequently 50 viral copies per milliliter. Assay upper limit is 750,000 copies $/ \mathrm{mL}$. At recruitment, SC21 had been on ART for 1 month and periods of STIs are shown with a gray background. (B) Left axis, dimeric rsFc $\gamma$ RIIIa binding (normalized AU, magenta symbols, $n=3$ ). Right axis, p24-stimulated $\mathrm{T}$ cell proliferation (red symbols) and (C) IFN $\gamma$ ELISPOTs $/ 10^{6}$ PBMCs stimulated with gag, pol, env, and nef peptides. Dimeric $\mathrm{rsF} \gamma \mathrm{R}$ activities at the indicated times were compared using an unpaired Mann-Whitney $t$-test, ${ }^{* *} p \leq .01$ and $* * * p<.001$. STI, structured treatment interruption. immune responses associated with viral containment, which are otherwise suppressed during continuous ART. With the aid of very frequent patient blood sampling during these STI cycles, we demonstrated boosting of both IgG responses, dimeric $\mathrm{rsFc} \gamma \mathrm{R}$ binding activity and $\mathrm{T}$ cell immunity, which contributed to virological control in some individuals. The study also confirmed that rapid decline in anti-envelope $\mathrm{Ab}$ titer occurs early during suppressive ART, but boosting of anti-Env Abs and $\mathrm{Fc} \gamma \mathrm{R}$ binding activities was achieved after only a few STI cycles, even when viral rebound was low (e.g., 460 copies/mL). Boosted dimeric $\mathrm{Fc} \gamma \mathrm{R}$ binding is indicative of increased IgG functionally during these STIs as these correlate with phagocytosis and natural killer (NK) cell ADCC activities. ${ }^{31-35,37,44}$

Therapeutic attempts to reactivate proviruses to clear viral reservoirs may benefit from non-neutralizing Abs with effector function against Env-expressing cells. While early initiation of ART is the essential standard care for HIV infection, it diminishes humoral and $\mathrm{Fc} \gamma \mathrm{R}$ functional responses. Although only partial virological control was achieved in these pilot studies (i.e., SC24 and SC84), the capacity for a small number of short STIs with low viral recrudescence (i.e., SC21) to rapidly boost $\mathrm{Ab}$ levels and dimeric $\mathrm{rsFc} \gamma \mathrm{R}$ binding (e.g., SC21, SC24, and SC84) can help to guide therapeutic approaches. Taken together, our data support the concept of viral antigen vaccination during ART as part of an HIV eradication strategy.

In addition to boosted $\mathrm{Ab}$ responses, it is notable that $\mathrm{T}$ cell responses were maintained after cessation of ART, and prolonged proliferative responses may suggest provision of $\mathrm{T}$ cell help for CTL and humoral control of viremia. However, Env-specific humoral responses proved more durable than helper T cell responses after ART was discontinued. We therefore propose that dimeric $\mathrm{Fc} \gamma \mathrm{R}$ binding could serve as a primary efficacy outcome measure in HIV-1 treatment and eradication strategies. A follow-up PBMC sample was not available to determine the long-term $\mathrm{T}$ cell response beyond 12 months without ART, but a plasma specimen taken 1 year after the study from SC84 demonstrated that humoral responses endured. A study of extended ART interruptions in chronically infected patients found boosted antibody titer, but not neutralization activity, suggesting that enhancement of 


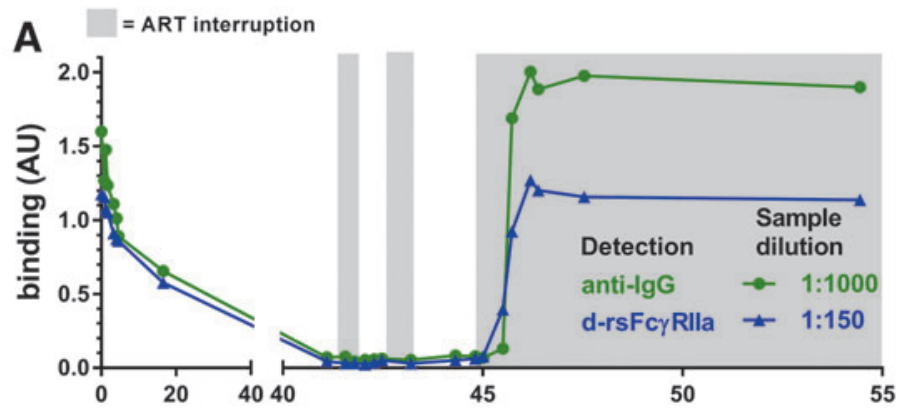

FIG. 6. Boosted $\mathrm{Ab}$, dimeric $\operatorname{rsFc} \gamma \mathrm{R}$ activity, and T cell immunity in STI in subject SC24 are contemporaneous with partial viral control. At recruitment, SC24 had been on ART for 6 months. STI periods of no ART are shown with the gray background. (A) Anti-IgG and dimeric rsFc $\gamma$ RIIa binding to Env opsonized at $1 / 1,000$ or $1 / 150$ sample dilution, respectively, is shown for 1 representative experiment. (B, C) Left axis, dimeric $\mathrm{rsFc} \gamma \mathrm{R}$ binding (filled triangles) to Env opsonized at $1 / 10$ sample dilution, mean \pm SEM, $n=6$, and nonspecific binding in the absence of Env (open triangles, $n=1$ ). Open circles show, placed arbitrarily on the $\mathrm{x}$-axis, background binding to Env treated with 1/10 HIV- serum samples $(n=3)$. (B) Right axis, viral load with dotted lines indicating the assay detection limits at 400 and subsequently 50 viral copies per milliliter. (C) Right axis, p24-stimulated T cell proliferation and (D) IFN $\gamma$ ELISPOTs $/ 10^{6}$ PBMCs stimulated with gag, pol, env, and nef peptides. Dimeric rsFc $\gamma \mathrm{R}$ activities at indicated times were compared using an unpaired Mann-Whitney $t$-test, $* * p \leq .01$.

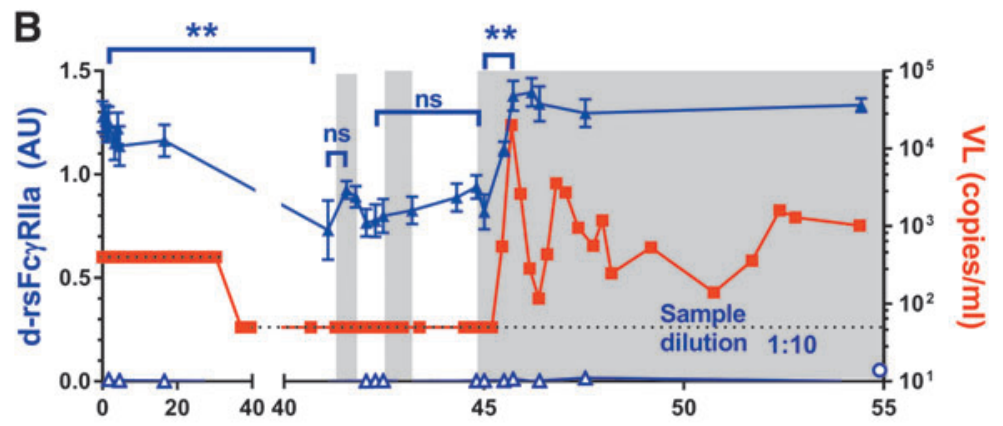

C
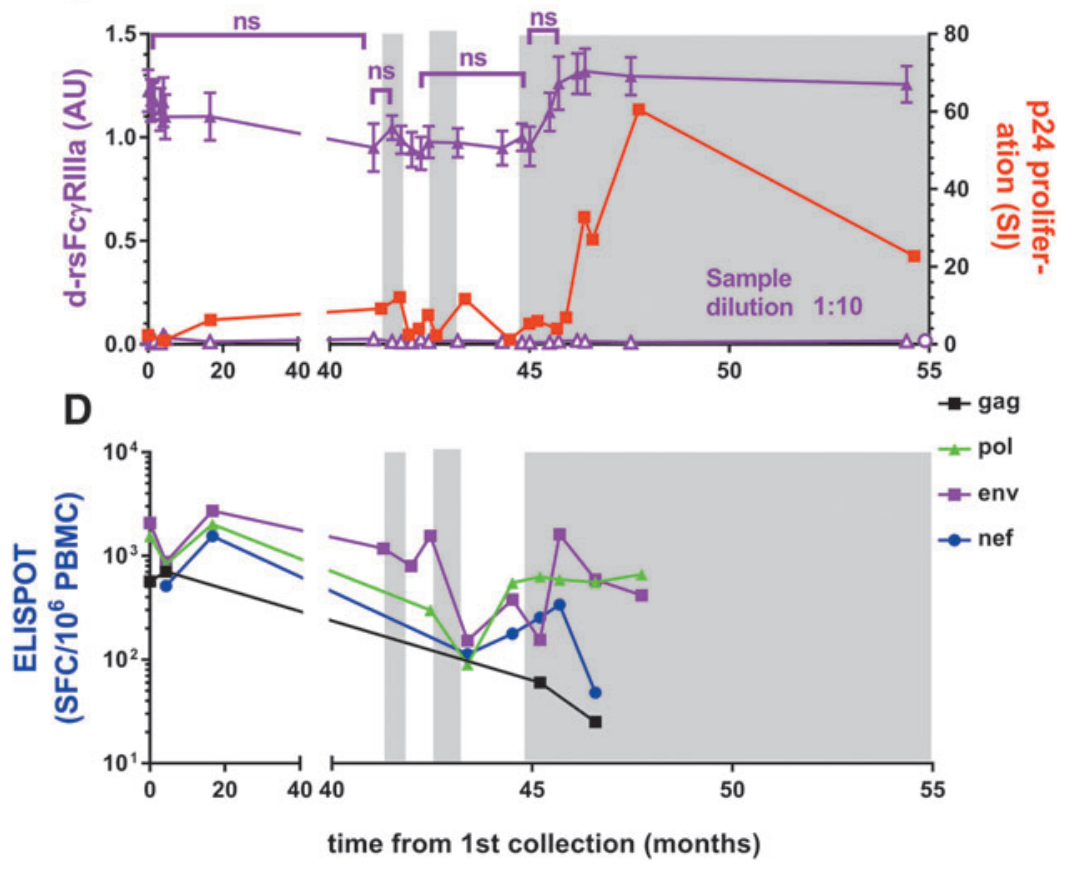

Fc-mediated function is the likely humoral outcome of antigen exposure during STI. ${ }^{45}$ Under the cover of ART, this could possibly be achieved by vaccination with newer recombinant forms of envelope proteins. It is encouraging that influenza A vaccination studies showed robust responses by ART patients. ${ }^{31}$

That a few short STI cycles provided some immune-based virological containment in this study could be attributed to high immunocompetence and early treatment in our participants. In ART-treated chronically infected subjects with elevated CD4 counts, four consecutive short (2 weeks) ART interruptions stimulated small increases in antibodies to

gp120 and more substantial increases were observed only after a fifth extended ART interruption. ${ }^{45}$ Our former study of panobinostat trial and SMART subjects found that longer ART interruption periods ( $>3$ weeks, $\sim 2$ months) with viral recrudescence to an estimated $\sim 300$ copies $/ \mathrm{mL}$ were required to stimulate increases in dimeric $\mathrm{rsFc} \gamma \mathrm{RIII}$ a binding. NK-mediated ADCC was significantly boosted only after 12 consecutive months of STI. ${ }^{46}$ In this current study, short STI intervals and low viremia (460 copies/mL in SC21) in some instances rapidly ( $<2$ weeks) boosted dimeric $r s F c \gamma R$ binding antibodies. Other studies described high T cell-based immunocompetence in some patients treated early after 


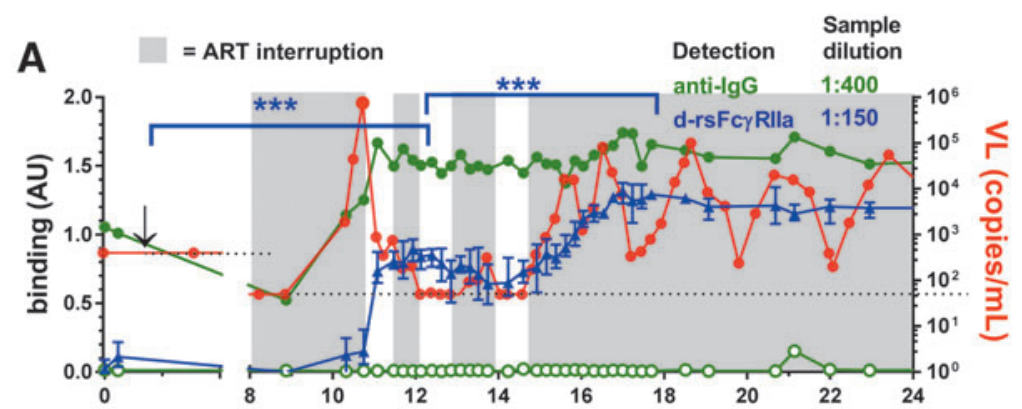

B
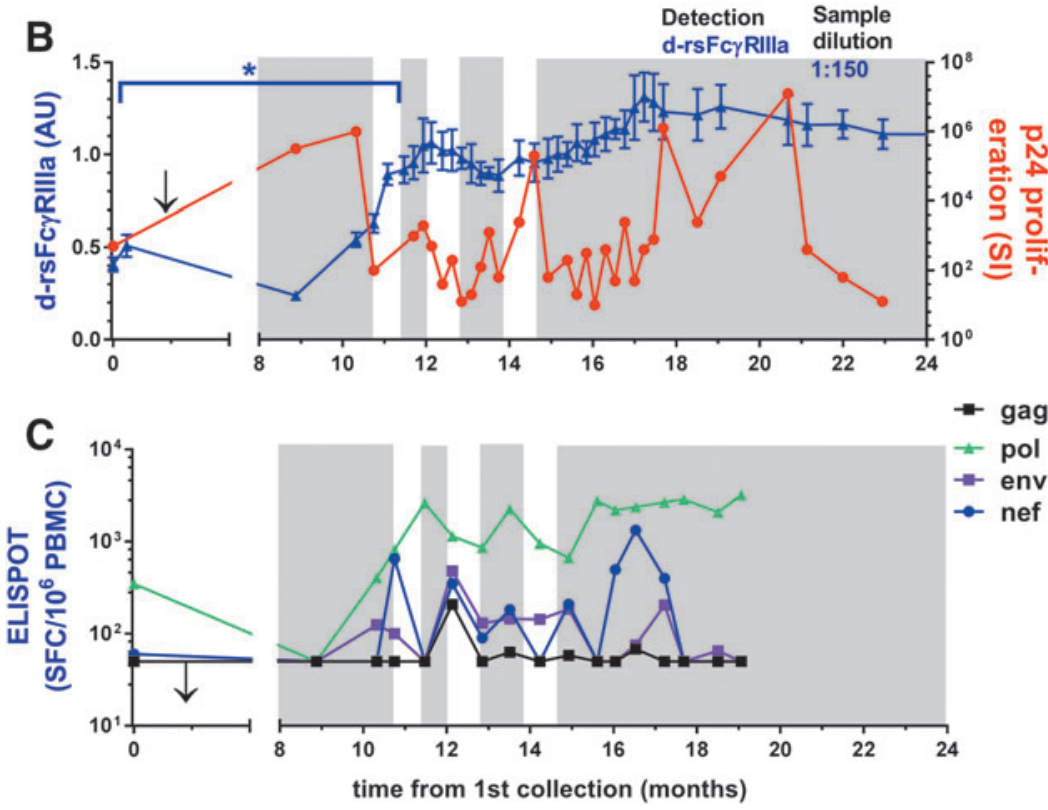

FIG. 7. STI in patient SC84 stimulates anti-Env IgG with dimeric $\mathrm{rsFc} \gamma \mathrm{R}$ binding activity, and sustained ART interruption is marked by episodic control of viremia. $(\mathbf{A}, \mathbf{B})$ Dimeric $\mathrm{rsFc} \gamma \mathrm{R}$ binding to Env opsonized at $1 / 150$ sample dilution, mean \pm range, $n=3$. (A) Left axis, dimeric rsFc $\gamma$ RIIa-H131 activity, normalized $\mathrm{AU}$, and anti-IgG1 binding to a $1 / 400$ dilution of samples with and without gp140 (green closed and open symbols, respectively); right axis, viral load with dotted lines indicating the assay detection limits at 400 and subsequently 50 viral copies per milliliter. The arrow marks the initiation of ART and periods of ART removal are shown with a gray background. (B) Left axis, dimeric rsFc $\gamma$ RIIIa activity, normalized AU, right axis $\mathrm{p} 24$-stimulated $\mathrm{T}$ cell proliferation and $(\mathbf{C})$ IFN $\gamma$ ELISPOTs $/ 10^{6}$ PBMCs stimulated with gag, pol, env, and nef peptides. Activities at indicated times were compared using an unpaired Mann-Whitney $t$-test, $* p<.05$ and $* * * p<.001$. infection in the T cell compartment, ${ }^{43}$ and in one case, partial virological control was associated with NAb raised during ART interruption. ${ }^{47}$

The dimeric $\mathrm{rsFc} \gamma \mathrm{R}$ assays used in this study recapitulate the intrinsic binding properties of cellular receptors combined with a requirement for two antibodies to present their Fc regions appropriately to be bridged by the receptor dimer. ${ }^{5}$ This was exemplified using near-saturating levels of three mAbs, which effectively opsonized gp140, but did not support dimeric rsFc $\gamma$ RIIa binding. Unlike the IgG titer, the dimeric $\mathrm{rsFc} \gamma \mathrm{R}$ assay is a unique measure that reflects two aspects of the functionality of the IgG response, namely the ability to bind each $\mathrm{Fc} \gamma \mathrm{R}$ and the extent of opsonization by pairs of closely spaced Abs. Such opsonization depends on multiple $\mathrm{Ab}$ specificities $(\geq 2)$ to appropriately spaced epitopes to be present in pAbs. Low dilution of samples allows high occupancy of gp140 to maximize formation of such IgG pairs. The slower loss of such dimeric $\mathrm{rsFc} \gamma \mathrm{R}$ binding compared with the anti-HIV IgG1 titer during ART indicates retention of $\mathrm{Ab}$ specificities in this diminishing titer. This polyclonality suggests that boosting of an existing diverse $\mathrm{Ab}$ response by vaccination under ART should be possible.

In two subjects with low initial anti-Env IgG1 titers (SC49 and SC74), the dimeric rsFc $\gamma$ RIIIa binding activity was greater compared with dimeric rsFc $\gamma$ RIIa. This indicates a qualitative difference in these early antibody responses. Favored dimeric $\mathrm{rsFc}_{\gamma} \mathrm{RIII}$ a binding activity may be due, in part, to the higher affinity of this receptor for $\operatorname{IgG}$ or specific glycosylation of the Fc region of $\mathrm{IgG}$ in the $\mathrm{Ab}$ response. The absence of a bisecting fucose in the Asn279-linked carbohydrate strongly increases Fc interaction with Fc $\gamma$ RIIIa and ADCC activities. ${ }^{48-51}$ Although levels of IgG3 were very low, the relative level of opsonizing anti-Env IgG3 to competing $\operatorname{IgG} 1$ was higher in these subjects. IgG3 opsonization of model immune complexes showed high dimeric $\mathrm{rsFc} \gamma \mathrm{R}$ binding, ${ }^{37}$ which possibly reflects the high effector functionality of this IgG subclass. ${ }^{52}$ While this pilot STI study does not allow further conclusions, this remains notable given the correlation of anti-Env of the IgG3 subclass with protection in the RV144 trial $^{19}$ and the IgG3 skewed anti-Env response in a subset of HIV controllers. ${ }^{53}$

This analysis of early ART-treated subjects found that while the Ab titer rapidly diminishes, a few short STIs were sufficient to boost immunity, including a marker of Fc $\gamma \mathrm{R}$ function. Boosting $\mathrm{Fc} \gamma \mathrm{R}$ function by Env protein vaccination during ART may be built into HIV-1 treatment and eradication strategies, and for this component, the dimeric $\mathrm{Fc} \gamma \mathrm{R}$ assay could define a standard, primary efficacy outcome.

\section{Acknowledgments}

This work was supported by grants from the Australian Centre for HIV and Hepatitis Virology Research $\left(\mathrm{ACH}^{2}\right)$, the National Health and Medical Research Council of Australia, 
and the Victorian Operational Infrastructure Scheme. The authors gratefully acknowledge the support of the Immunovirology Research Network of the Australian Centre for HIV and Hepatitis Virology Research.

\section{Author Disclosure Statement}

No competing financial interests exist.

\section{References}

1. Nimmerjahn F, Ravetch JV: Fcgamma receptors as regulators of immune responses. Nat Rev Immunol 2008;8: 34-47.

2. Ravetch JV, Bolland S: IgG Fc receptors. Annu Rev Immunol 2001;19:275-290.

3. Nimmerjahn F, Ravetch JV: Divergent immunoglobulin g subclass activity through selective $\mathrm{Fc}$ receptor binding. Science 2005;310:1510-1512.

4. Hogarth PM, Pietersz GA: Fc receptor-targeted therapies for the treatment of inflammation, cancer and beyond. Nat Rev Drug Discov 2012;11:311-331.

5. Wines BD, Billings H, McLean MR, Kent SJ, Hogarth PM: Antibody functional assays as measures of Fc receptormediated immunity to HIV-New technologies and their impact on the HIV vaccine field. Curr HIV Res 2017;15: 202-215.

6. Parsons MS, Chung AW, Kent SJ: Importance of Fcmediated functions of anti-HIV-1 broadly neutralizing antibodies. Retrovirology 2018;15:58.

7. Hessell AJ, Poignard P, Hunter M, et al.: Effective, lowtiter antibody protection against low-dose repeated mucosal SHIV challenge in macaques. Nat Med 2009;15: 951-954.

8. Hessell AJ, Hangartner L, Hunter M, et al.: Fc receptor but not complement binding is important in antibody protection against HIV. Nature 2007;449:101-104.

9. Gomez-Roman VR, Patterson LJ, Venzon D, et al.: Vaccine-elicited antibodies mediate antibody-dependent cellular cytotoxicity correlated with significantly reduced acute viremia in rhesus macaques challenged with SIVmac251. J Immunol 2005;174:2185-2189.

10. Barouch DH, Stephenson KE, Borducchi EN, et al:: Protective efficacy of a global HIV-1 mosaic vaccine against heterologous SHIV challenges in rhesus monkeys. Cell 2013; 155:531-539.

11. Sips M, Krykbaeva M, Diefenbach TJ, et al.: Fc receptormediated phagocytosis in tissues as a potent mechanism for preventive and therapeutic HIV vaccine strategies. Mucosal Immunol 2016;9:1584-1595.

12. Lu CL, Murakowski DK, Bournazos S, et al.: Enhanced clearance of HIV-1-infected cells by broadly neutralizing antibodies against HIV-1 in vivo. Science 2016;352:10011004.

13. Schoofs $\mathrm{T}$, Klein $\mathrm{F}$, Braunschweig $\mathrm{M}$, et al:: HIV-1 therapy with monoclonal antibody 3BNC117 elicits host immune responses against HIV-1. Science 2016;352:9971001 .

14. Jaworski JP, Cahn P: Preventive and therapeutic features of broadly neutralising monoclonal antibodies against HIV-1. Lancet HIV 2018;5:e723-e731.

15. Haynes BF, Gilbert PB, McElrath MJ, et al:: Immunecorrelates analysis of an HIV-1 vaccine efficacy trial. N Engl J Med 2012;366:1275-1286.
16. Yates NL, Liao HX, Fong Y, et al.: Vaccine-induced Env V1-V2 IgG3 correlates with lower HIV-1 infection risk and declines soon after vaccination. Sci Transl Med 2014;6: 228 ra239.

17. Zolla-Pazner S, deCamp A, Gilbert PB, et al.: Vaccineinduced IgG antibodies to V1V2 regions of multiple HIV-1 subtypes correlate with decreased risk of HIV-1 infection. PLoS One 2014;9:e87572.

18. Rerks-Ngarm S, Pitisuttithum P, Nitayaphan S, et al.: Vaccination with ALVAC and AIDSVAX to prevent HIV-1 infection in Thailand. N Engl J Med 2009;361:2209-2220.

19. Chung AW, Ghebremichael M, Robinson H, et al:: Polyfunctional Fc-effector profiles mediated by IgG subclass selection distinguish RV144 and VAX003 vaccines. Sci Transl Med 2014;6:228ra238.

20. Hammer SM, Squires KE, Hughes MD, et al.: A controlled trial of two nucleoside analogues plus indinavir in persons with human immunodeficiency virus infection and CD4 cell counts of 200 per cubic millimeter or less. AIDS Clinical Trials Group 320 Study Team. N Engl J Med 1997; 337:725-733.

21. Gallo RC: Shock and kill with caution. Science 2016;354: 177-178.

22. Shan L, Deng K, Shroff NS, et al.: Stimulation of HIV-1specific cytolytic $\mathrm{T}$ lymphocytes facilitates elimination of latent viral reservoir after virus reactivation. Immunity 2012;36:491-501.

23. Wykes MN, Lewin SR: Immune checkpoint blockade in infectious diseases. Nat Rev Immunol 2018;18:91-104.

24. Bournazos S, Klein F, Pietzsch J, Seaman MS, Nussenzweig MC, Ravetch JV: Broadly neutralizing anti-HIV-1 antibodies require Fc effector functions for in vivo activity. Cell 2014;158:1243-1253.

25. Horwitz JA, Bar-On Y, Lu CL, et al:: Non-neutralizing antibodies alter the course of HIV-1 infection in vivo. Cell 2017;170:637-648 e610.

26. Morris L, Binley JM, Clas BA, et al.: HIV-1 antigenspecific and -nonspecific $B$ cell responses are sensitive to combination antiretroviral therapy. J Exp Med 1998;188: 233-245.

27. Adalid-Peralta L, Grangeot-Keros L, Rudent A, et al: Impact of highly active antiretroviral therapy on the maturation of anti-HIV-1 antibodies during primary HIV-1 infection. HIV Med 2006;7:514-519.

28. Killian MS, Norris PJ, Rawal BD, et al:: The effects of early antiretroviral therapy and its discontinuation on the HIV-specific antibody response. AIDS Res Hum Retroviruses 2006;22:640-647.

29. Madhavi V, Ana-Sosa-Batiz FE, Jegaskanda S, et al.: Antibody-dependent effector functions against HIV decline in subjects receiving antiretroviral therapy. J Infect Dis 2015;211:529-538.

30. Madhavi V, Kulkarni A, Shete A, et al.: Effect of combination antiretroviral therapy on HIV-1-specific antibodydependent cellular cytotoxicity responses in subtype B- and subtype C-infected cohorts. J Acquir Immune Defic Syndr 2017;75:345-353.

31. Kristensen AB, Lay WN, Ana-Sosa-Batiz F, et al.: Antibody responses with Fc-mediated functions after vaccination of HIV-infected subjects with trivalent influenza vaccine. J Virol 2016;90:5724-5734.

32. Vanderven HA, Liu L, Ana-Sosa-Batiz F, et al:: Fc functional antibodies in humans with severe H7N9 and seasonal influenza. JCI Insight 2017;2:92750. 
33. Vanderven HA, Jegaskanda S, Wines BD, et al.: Antibodydependent cellular cytotoxicity responses to seasonal influenza vaccination in older adults. J Infect Dis 2017;217: $12-23$.

34. Madhavi V, Wines BD, Amin J, et al:: HIV-1 Env- and Vpu-specific antibody-dependent cellular cytotoxicity responses associated with elite control of HIV. J Virol 2017; 91:e00700-17.

35. Vanderven HA, Ana-Sosa-Batiz F, Jegaskanda S, et al.: What lies beneath: Antibody dependent natural killer cell activation by antibodies to internal influenza virus proteins EBioMedicine 2016;8:277-290.

36. Anand SP, Prevost J, Baril S, et al:: Two families of Env antibodies efficiently engage Fc-gamma receptors and eliminate HIV-1-infected cells. J Virol 2019;93:e01823-18.

37. Wines BD, Vanderven HA, Esparon SE, Kristensen AB, Kent SJ, Hogarth PM: Dimeric FcgammaR ectodomains as probes of the $\mathrm{Fc}$ receptor function of anti-influenza virus IgG. J Immunol 2016;197:1507-1516.

38. Pai NP, Tulsky JP, Lawrence J, Colford JM, Jr., Reingold AL: Structured treatment interruptions (STI) in chronic suppressed HIV infection in adults. Cochrane Database Syst Rev 2005:CD005482.

39. Patel D, Wines BD, Langley RJ, Fraser JD: Specificity of staphylococcal superantigen-like protein 10 toward the human IgG1 Fc domain. J Immunol 2010;184:6283-6292.

40. Kramski M, Center RJ, Wheatley AK, et al.: Hyperimmune bovine colostrum as a low-cost, large-scale source of antibodies with broad neutralizing activity for HIV-1 envelope with potential use in microbicides. Antimicrob Agents Chemother 2012;56:4310-4319.

41. Center RJ, Wheatley AK, Campbell SM, et al.: Induction of HIV-1 subtype B and AE-specific neutralizing antibodies in mice and macaques with DNA prime and recombinant gp140 protein boost regimens. Vaccine 2009;27:66056612.

42. Dyer WB, Zaunders JJ, Yuan FF, et al.: Mechanisms of HIV non-progression; robust and sustained CD4+ T-cell proliferative responses to p24 antigen correlate with control of viraemia and lack of disease progression after long-term transfusion-acquired HIV-1 infection. Retrovirology 2008; 5:112.

43. Dyer WB, Kuipers H, Coolen MW, et al.: Correlates of antiviral immune restoration in acute and chronic HIV type 1 infection: Sustained viral suppression and normalization of T cell subsets. AIDS Res Hum Retroviruses 2002;18: 999-1010.

44. McLean MR, Madhavi V, Wines BD, Hogarth PM, Chung AW, Kent SJ: Dimeric Fcgamma receptor enzyme-linked immunosorbent assay to study HIV-specific antibodies: A new look into breadth of Fcgamma receptor antibodies induced by the RV144 vaccine trial. J Immunol 2017;199: $816-826$.

45. Trkola A, Kuster H, Leemann C, et al.: Humoral immunity to HIV-1: Kinetics of antibody responses in chronic infection reflects capacity of immune system to improve viral set point. Blood 2004;104:1784-1792.

46. Lee WS, Kristensen AB, Rasmussen TA, et al.: Anti-HIV-1 ADCC antibodies following latency reversal and treatment interruption. J Virol 2017;91:e00603-17.

47. Montefiori DC, Altfeld M, Lee PK, et al:: Viremia control despite escape from a rapid and potent autologous neutralizing antibody response after therapy cessation in an HIV-1-infected individual. J Immunol 2003;170:39063914.

48. Chung AW, Crispin M, Pritchard L, et al.: Identification of antibody glycosylation structures that predict monoclonal antibody Fc-effector function. AIDS 2014;28:2523-2530.

49. Shinkawa T, Nakamura K, Yamane N, et al.: The absence of fucose but not the presence of galactose or bisecting $\mathrm{N}$-acetylglucosamine of human IgG1 complex-type oligosaccharides shows the critical role of enhancing antibodydependent cellular cytotoxicity. J Biol Chem 2003;278: 3466-3473.

50. Ferrara C, Stuart F, Sondermann P, Brunker P, Umana P: The carbohydrate at FcgammaRIIIa Asn-162. An element required for high affinity binding to non-fucosylated $\mathrm{IgG}$ glycoforms. J Biol Chem 2006;281:5032-5036.

51. Ferrara C, Grau S, Jager C, et al.: Unique carbohydratecarbohydrate interactions are required for high affinity binding between FcgammaRIII and antibodies lacking core fucose. Proc Natl Acad Sci U S A 2011;108:12669-12674.

52. Irani V, Guy AJ, Andrew D, Beeson JG, Ramsland PA, Richards JS: Molecular properties of human IgG subclasses and their implications for designing therapeutic monoclonal antibodies against infectious diseases. Mol Immunol 2015; 67(Pt A):171-182.

53. Banerjee K, Klasse PJ, Sanders RW, et al.: IgG subclass profiles in infected HIV type 1 controllers and chronic progressors and in uninfected recipients of Env vaccines. AIDS Res Hum Retroviruses 2010;26:445-458.

Address correspondence to: P. Mark Hogarth, PhD Immune Therapies Group Life Sciences, Burnet Institute 85 Commercial Road Melbourne, Vic 3004 Australia

E-mail: mark.hogarth@burnet.edu.au 